\title{
Self-Identity Construction of Indonesian Migrant Workers in the Destination Country
}

\author{
Tutik Sulistyowati \\ University of Muhammadiyah Malang, Indonesia \\ sulistyowati_tutik@yahoo.co.id
}

\begin{abstract}
This study aims to review the construction of self-identity of migrant workers in the destination country. The methodology applied was interpretative paradigm with phenomenology approach. The subjects were selected by using purposive sampling technique. Then, the data were collected by using in depth-interview and analyzed by using descriptive qualitative research design. The result of the study showed that the subject who worked in Hong Kong had a good understanding towards the culture, the concept of migrant workers, the communication as well as problem-solving skill of destination country. It was proven by the self-identity construction of migrant workers. Meanwhile, few Malaysian and Saudi Arabian workers completely had implemented those concepts. The subjective dialectics in objective reality are more likely to occur to individuals who worked in Hong Kong due to social condition which is more transparent. The working system gives work off for all migrant workers to meet one another. Thus, the meeting among subjects might strengthen the construction of self-identity. Therefore, the subjects who actively interpret the experience and environment vis-à-vis personal experience could strongly enforce their social construction.
\end{abstract}

\section{Keywords: self-identity, construction, migrant workers}

\section{INTRODUCTION}

Indonesia is a top sending country of migrant workers overseas despite the various problems this country still encounters. As a result, Indonesian government has established legislation for labor protection. However, the study conducted indicates inadequacy of the labor protection before and after placement [1]. The failure of protection policy for migrant workers needs to be reviewed.Therefore, this policy needs a great attention in both subjective and objective point of view. Objectively, the protection policy from a country has to be clarified as well as subjective aspect.In term of subjective perception, both interaction and social behavior of migrant workers in a new place should be mainly considered.For instance, languages, norms, social values, and cultural differences become serious problemsif there is no preventive treat.

Worker migration is a human movement across the region to look for jobs in the destination country. Migrant workers give such economic contribution for both receiving and sending country either officially or unofficially. Moreover, they increase the number of workforces in the destination country and assist the establishment of infrastructures in their own country.Particularly, migrant workershave social identity before moving to theirdestination country. They need to construct their social identity in theirdestination country. There are several things to be concerned before constructing self-identity, namely regulation understanding, social value adjustment, language proficiency, and negotiation competence.

This study aims to focus on subjective side of migrant workers regarding self-identity construction in social life of current country.Self-identity is personal information formed by current period which is related to past and present, which could be classified but not be separated from social identity in the community context. Human constructsself-identity based on not only personal description, but also cultural values and normsrestricting society in the same living place [2].

Based on the previous study, the emergence of Indonesian migrant workers' problems in the destination country is mostly influenced by subjective and objective factors. This phenomenon happens to Indonesian migrant workers who are mostly inexperienced, having low education level, and coming from rural areas. Consequently, they slowly learn and adopt social values, norms, and cultures in a new place subjectively [3]. Furthermore, these workers have no self-awareness and knowledgerelated to their jobs. Otherwise, the objective factors are mostly related to the differences between social culture, economics, politics, and law in receiving and sending country. These differences would create internal conflictsamong migrant workersas they mayalso experience culture shock in the destination country.

(who?) stated that cultural factors would influence one's self-identity. As a result, self-identityis formed throughsocial interaction. Meanwhile, a man who lives alone and dissociates himself from social interaction will not obtain self-identity because it will be appeared in social life [4].Culture, a social identity tool, would give a great influence towards individual development.A person, in a new place, must engage with socialization and internalization process towards social values and behaviors of society. The output of this internalization process would be reflected on daily life and could create personal and social knowledge together. This context yields internalization, externalization, and social objective process [5].

Theoretically, personal concept is reflected through interaction in social life. Theory of symbolic interactionism revealed that personal concept could be developed through interaction between people and performancesof crucial motives for personal behaviors [6]. Migrant workers' ability to adopt cultural values and awareness in a new place is expected to strongly construct and implement self-identity in social activities. A person (with self-identity) who has commitment of moral values issues will reflect these values into social reality, mentality, and reflection[7].This study is a 
micro perspective of sociological literature. It mainly concerns on self-awareness and knowledge of migrant workers to construct self-identity in the destination country.

\section{METHOD}

This study uses interpretative paradigm that attempts to interpret and comprehend social actsamong social relations to achieve the causal explanation. Interpretative paradigm views facts as a unique content which has both special context and meaning as the 'essence' to comprehend social understanding. Through this paradigm, the researcher must be able to capture the interpretation process and see everything through the subjects' point of view.

The study approach employed phenomenology in revealing the abstract and symbolic data. The study applied qualitative design.The data employed in this study were qualitative which are related to the subjects' knowledge, perception, and belief, as well as communication skillsoccurred.

The main objective of this study is to explore the subjects' interpretation, knowledge and understanding. It is expected to become the framework basic of migrant workers' self-identity in shaping work behavior and attitude in the destination country. Therefore, the initial stage of the study puts aside public opinion.

The subjects of the study wereselected by using purposive sampling under criteria: (1) female migrant workers who return to Indonesia for holiday, (2) those who are working in Malaysia, Saudi Arabia, and Hong Kong, (3) those working as housemaids, and living with their employers. The settings of the study were East Java regions where the migrant workers come from; Malang, Blitar and Tulungagung. The data collection technique used in the study was in-depth interview in Indonesia and Hong Kong that conveyed "getting in", "getting along" and "letting her describe herself" stages.

The data analysis in this study employed interactive analysis that was done by observing interaction and dialectics patterns between I (migrant workers) and them (social environment) in their destination countries. Categorical development was done inductively to generate relevant themes with empiric data as understood by the subjects' perspective. Thus, inductive approach was taken as the main strategy in organizing all data in certain levels, which later were used as the basis of generating relevant concept and theory toward reviewed reality.

This study was conducted by implementing naturalistic research and did not include trinity principle (principle in qualitative research tradition, i.e. validity, reliability and generalization). The trinity principle in qualitative study alienates self experience from "knowing" activity of certain individuals [8].A qualitative study depends on the descriptive presentation of solid data allowing the researcher to deliver a clear understanding towards subjects' experiences observed.The description of meaning interpretation of individual cases, places and events experienced by the subjects of the study were taken as the basis of the qualitative study.

\section{RESULTS AND DISCUSSION}

The study revealed that: (1) the majority of subjects who work in Hong Kong possessed the understanding of local culture of their roles as migrant workers, were able to communicate in the official language, were capable of adapting to employers' family, and were competent in overcoming problems. Therefore, it can be inferred that the majority of subjects who work in Hong Kong are capable of constructingself-identity. (2) Only few subjects who work in Saudi Arabia had good understanding and the ability to adapt to local culture, while the rest of them could not speak Arabic, had low level of communication skill, tended to use body language, hardly adapted to local culture, tended to avoid the employers, were being diffident, and were lack of motivation to learn new things and to adapt to new environments. (3) The majority of subjects who work in Malaysia were lack of understanding and self-awareness. They assumed that the country where they work did not different from Indonesia. They had low level of communication and adaptation skill. They tended to avoid the employers, were being diffident and there was no motivation to learn new things. In understanding the legislation of rights and liabilities, the subjects in all mentioned destination countries subjectively only understood their rights of getting paid monthly and their liabilities of obeying the employers.

The subjects who work in Hong Kong had better ability to construct self-identity than those working in Malaysia and Saudi Arabia, this is influenced by some factors: (1) Hong Kong culture is more democratic and open than Malaysian and Saudi Arabian, (2) The migrant workers in Hong Kong are given day off every Sunday. This privilege is used by them to get along with each other, to share stories, to discuss the potential issues they might encounter related to daily works and new environments.

The concept of phenomenology reveals that people who actively interpret their experiences and attempt to understand the environment based on personal experience are those who are capable of constructing the important meaning and concept in their intersubjectivities [8]. The ability of the subjects in comprehending Malaysian, Hong Kong, and Saudi Arabian cultures and then deploying it as daily basic interaction in their intersubjectivities is an indicator of individuals who are able to construct self-identity in social interaction. Subjects' experiences are knowledge that not only derives from external experiences, but also from the internal ones reflected in social acts.

Subjectively, the awareness and comprehension on one's self-identity are important in fulfilling daily obligations. They influence the confidence in engaging professionalism. This corresponds to the result of the study conducted by [9] which shows that stigma can influence the development of one's professional identity. Professional identity is defined as an identity that has self concept based on attributes, faith, values, motives, and experiences. These aspects are used as the basic work guidelines in order to achieve professionalism.

Objectively, the migrant workers who are able to discover self potentials should negotiate with other people in new 
environments and improvise creatively since they are crosscultural agents. The active negotiation and improvisation will occur in daily social interactions. A migrant worker brings various interests transcendentally through enigmatic life [10]. This study perceives the migrant workers as people who encounter dilemma where on one side they have to adapt to a new culture while on the other side they are incapable of abandoning their own cultures. A study conducted by [11] shows that the state supervision strategy forms the identity construction of migrant workers in France. This study contradicts the results of this study on construction of identity, for the construction of individual identity cannot be established by the state but rather by the ability of individuals in everyday social interaction in the environment. Self-identity is a thing that exists within a person and is dynamically developing in social life.

The understanding towards someone's act is not only based on the internal influence but also on external one in social and cultural environment during the lifetime [8]. Consequently, the result of subjects' interaction, attitude, and act differ in each country. The subjects who work in an open and democratic country are able to construct self-identity easier than those living in a conservative one since it is not easy to find meaning and understanding of the social reality. (who?) states that social act is an act regarding the moment when someone starts to reflect the reduced world and figures out that the world is full of meanings and values that are generated intersubjectively [12].

\section{CONCLUSION}

The study concluded that subjects could not construct theirself-identity in a new environment, especially those who work in Malaysia and Saudi Arabia, because there is no workoff in those countries for migrant workers. This could create some subjective cases among them. But in Hong Kong, there is a chance for them to meet and tell each other's stories about work, experience, and their problems, so they have information to overcome their problems. Selfidentityconstruction depends on the subjective ability of individuals in knowing, understanding, adopting, negotiating, and implementing social values, cultures, norms, and languages in new social environments. The interaction process between an individual and his or her group is crucial in forming the individual's self-identity. Subjective empowerment on the ability of the subjects in constructing themselves to social environment of the destination countries can be conducted preventively by the government in their home countries.

\section{REFERENCES}

[1] A. S. Azmi,Negara dan Buruh Migran Perempuan. 2012.

[2] P. Weinreich and W. Saunderson, Analysing Identity: Cross-Cultural, Societal and Clinical Contexts. 2003

[3] T.Sulistyowati, MaknaSosialEkonomi Tenaga MigranbagiKeluargadanMasyarakat. 2001.

[4] P. L. Berger andT. Luckmann,TafsirSosialAtasKenyataan: RisalahtentangSosiologiPengetahuan. 1990.

[5] G. H. Mead, The Genesis Self in C. Gordon \& K. J. Gergen. The Self in Social Interaction. 1968.

[6] S. Brinkmann, "Identity as Self-Interpretation," Theory \& Psychology, 18(3), pp.404-422, 2008.

[7] N. K. Denzin, Handbook of Qualitative Research. 2009.

[8] A. Schutz, in John Wild, The Phenomenology of the Social World. 1967.

[9] H. S.Slayand D. A. Smith, "Professional identity construction: Using narrative to understand the negotiation of professional and stigmatized cultural identities, ”Journal of HUM, SAGE Publication.2004.

[10] A. S. Gronsenth, Being Human Being Migrant: Sense of Self and Well Being. 2013.

[11] C. F. Sargent andS. Larchanché-Kim,Immigration Status, Gender, and the Construction of Identities Among Malian Migrants in Paris. 2010.

[12] T. Postmes, S.A. Haslam, and R. I. Swaab, The Dynamics of Personal and Social Identity Formation. In Postmes \& J. Jetten (Eds.) Individual ang the group advances in SociaIdentity, 2005 